\title{
Common NOD2/CARD I 5 variants are not associated with susceptibility or the clinicopathologic characteristics of sporadic colorectal cancer in Hungarian patients
}

\author{
Peter Laszlo Lakatos*1, Erika Hitre2, Ferenc Szalay¹, Kerstin Zinober ${ }^{3}$, \\ Peter Fuszek ${ }^{1}$, Laszlo Lakatos ${ }^{4}$, Simon Fischer ${ }^{1}$, Janos Osztovits ${ }^{1}$, \\ Orsolya Gemela ${ }^{1}$, Gabor Veres ${ }^{5}$, Janos Papp ${ }^{1}$ and Peter Ferenci ${ }^{3}$
}

\begin{abstract}
Address: ${ }^{1} 1$ st Department of Medicine, Semmelweis University, Budapest, Hungary, ${ }^{2}$ National Institute of Oncology, Budapest, Hungary, ${ }^{3}$ Department of Internal Medicine 4, University of Vienna, Austria, ${ }^{4} 1$ st Department of Medicine, Csolnoky F. County Hospital, Veszprem, Hungary and ${ }^{5} 1$ st Department of Pediatrics, Semmelweis University, Budapest, Hungary

Email: Peter Laszlo Lakatos* - kislakpet@yahoo.com; Erika Hitre - hitre@oncol.hu; Ferenc Szalay - szalay@bel1.sote.hu; Kerstin Zinober - kislakpet@yahoo.com; Peter Fuszek - fuszpet@bel1.sote.hu; Laszlo Lakatos - lakatos.laszlo@vmkorhaz.hu; Simon Fischer - sfischer712@yahoo.ca; Janos Osztovits - osztoka@yahoo.co.uk; Orsolya Gemela - gemiorsi@freemail.hu; Gabor Veres - vergab@gyer1.sote.hu; Janos Papp - papjan@bel1.sote.hu; Peter Ferenci - peter.ferenci@meduniwien.ac.at

* Corresponding author
\end{abstract}

Published: 27 March 2007

BMC Cancer 2007, 7:54 doi:10.1/86/147|-2407-7-54
Received: 18 October 2006

Accepted: 27 March 2007

This article is available from: http://www.biomedcentral.com/I47I-2407/7/54

(c) 2007 Lakatos et al; licensee BioMed Central Ltd.

This is an Open Access article distributed under the terms of the Creative Commons Attribution License (http://creativecommons.org/licenses/by/2.0), which permits unrestricted use, distribution, and reproduction in any medium, provided the original work is properly cited.

\begin{abstract}
Background: Epidemiological observations suggest that cancer arises from chronically inflamed tissues. Inflammatory bowel disease (IBD) is a typical example as patients with longstanding IBD are at an increased risk for developing colorectal cancer (CRC) and mutations of the NOD2/CARD/5 gene increase the risk for Crohn's disease (CD). Recently, NOD2/CARD I 5 has been associated with a risk for CRC in some studies, which stemmed from ethnically diverse populations. Our aim was to identify common NOD2/CARD/5 mutations in Hungarian patients with sporadic CRC.
\end{abstract}

Methods: A total of 194 sporadic CRC patients (m/f: 108/86, age at diagnosis of CRC: $63.2 \pm 9.1$ years old) and 200 healthy subjects were included. DNA was screened for SNP8, SNPI 2 and SNPI3 NOD2/CARD/ 5 mutations by denaturing-HPLC and confirmed by direct sequencing.

Results: NOD2/CARD / 5 mutations were found in 28 patients (14.4\%) and in 23 controls (11.5\%, P $=\mathrm{NS}$ ). Allele frequencies for SNP8/R702W (I.8\% vs. I.5\%) SNPI $2 / G 908 R(1.8 \%$ vs. $1.8 \%)$ and SNPI $3 / 3020$ ins C (3.6\% vs. $2.5 \%$ ) were also not statistically different between patients and controls. The clinicopathologic characteristics of CRC patients with or without NOD2/CARD /5 mutations were not significantly different.

Conclusion: Our results suggest that common NOD2/CARD / 5 mutations alone do not contribute to $C R C$ risk in the Hungarian population.

\section{Background}

Colorectal adenocarcinoma (CRC) is the second most common cause of death in developed countries. It is pre- ceded only by lung cancer in mortality statistics as the leading cause of malignant deaths. Approximately 700,000 new cases are discovered and almost half a mil- 
lion patients die of the disease each year [1]. In Hungary, CRC mortality has almost tripled in the past four decades, with a great proportion of the patients being diagnosed only in advanced stages [2]. The pathogenesis of sporadic CRCs is thought to be multifactorial, with multiple genetic and various environmental factors involved [3-5].

Epidemiological studies have suggested that chronic continuous inflammation predisposes to cancer [6]. A typical example is the association between inflammatory bowel diseases (IBD) and colorectal cancer (CRC) [7]. Although CRC, complicating ulcerative colitis and Crohn's disease, accounts for only $1-2 \%$ of all cases of CRC in the general population, it is considered a serious complication of the disease accounting for 1 in 6 of all deaths in IBD patients $[8,9]$. Precursor lesions of CRC may often have inflammatory histological features [10]. Inflammation may favour tumorigenesis by inducing DNA damage [11] stimulating continuous cell proliferation or apoptosis [12] and stimulating angiogenesis.

Assuming that the underlying chronic inflammation in IBD may be implicated in the progression of CRC, genetic factors, known to be involved in the chronic inflammatory process in ulcerative colitis and Crohn's disease, may simultaneously hasten the development of CRC in IBD patients. Several studies have shown that NOD2/CARD15, a gene that overlaps with the IBD1 locus on chromosome $16 \mathrm{q} 12$, is significantly associated with susceptibility to IBD [13]. The physiological role of the CARD15/NOD2 protein remains under detailed examination. It is a cytoplasmic protein expressed in peripheral blood monocytes, Paneth cells and intestinal epithelial cells, and is structurally related to the well-described $\mathrm{R}$ proteins in plants, which mediate host resistance to microbial pathogens [14]. Variant alleles result in altered NF- $\mathrm{KB}$ activity $[15,16]$. Variant NOD2/CARD15 alleles are also associated with reduced $\alpha$-defensin secretion from Paneth cells in response to bacteria [17]. Finally, NOD2/CARD15 was found to be involved in the regulation of TLR2 [18] and carriers of the variant alleles exhibited increased intestinal permeability [19].

Two single-nucleotide polymorphisms of NOD2/CARD15 (SNP8: R702W and SNP12: G908R) and a frameshift mutation (SNP13: 3020insC) were shown by independent groups to be associated with susceptibility to CD $[20,21]$. The presence of one variant allele increases the risk of developing CD 1.5-4.3-fold, and of two copies by up to $20-40$-fold [22,23], yet rates are lower in Northern Europe [24].

Recently, NOD2/CARD15 was found to increase the risk for colorectal cancer (CRC). Kurzawski et al. [25] found that the presence of 3020ins $\mathrm{C}$ mutation increased the risk of developing CRC by 2.23-fold in Polish patients with an older average age at diagnosis. This was however not confirmed in a Finnish study by Alhopuro et al. [26]. Noteworthy, in the most recent Greek study, all three common variants were found to be associated with an increased risk for CRC (OR: 2.4-5.2) [27].

In light of these findings, and given that the frequency of the mutations varies in different populations, our aim was to investigate the presence of the three common NOD2/ CARD15 variants in a large cohort of patients with sporadic CRC in Hungary, a country with a high CRC incidence rate, comparable to that observed in Poland.

\section{Methods}

One hundred and ninety-four consecutive Caucasian patients with sporadic CRC were investigated (male/ female: 108/86, age at diagnosis of CRC: $63.2 \pm 9.1$ years old). All patients with known hereditary cancer syndromes and previous diagnosis of IBD or a positive family history of CRC were excluded. The clinical data, symptoms (hematochezia, weight loss, anemia, changes in bowel movement habits) and clinicopathologic characteristics of the patients are shown in Table 2.

The control group for mutation analysis consisted of 200 gender-matched healthy Caucasian subjects (male/ female: 102/98), without any known gastrointestinal disease. Also colorectal cancer was absent in the family history of controls [23]. The study was approved by the Semmelweis University Regional and Institutional Committee of Science and Research Ethics. Each patient was informed on the nature of the study and signed the informed consent form.

\section{Detection of NOD2/CARDI5 SNP8, SNPI 2 and I3 mutations}

Genomic DNA was isolated from whole blood according to the QIAamp DNA blood mini kit (QIAGEN GmbH, Germany). Each exon was amplified by PCR using previously published primer sequences [23]. The initial denaturation step (at $94^{\circ} \mathrm{C}$ for $7 \mathrm{~min}$ ) was necessary in order to activate the AmpliTaq Gold (Applied Biosystems, Foster City, CA, USA), followed by 33 cycles (at $94^{\circ} \mathrm{C}$ for 20 $\mathrm{s}$, at $61^{\circ} \mathrm{C}$ for $30 \mathrm{~s}$, at $72^{\circ} \mathrm{C}$ for $25 \mathrm{~s}$ ) with a final extension step at $72^{\circ} \mathrm{C}$ for $7 \mathrm{~min}$. Then, denaturing high-performance liquid chromatography (dHPLC, wave DNA fragment analysis system, Transgenomic Limited, UK) was performed to analyze the exons. In the final step, PCR products were denatured at $94^{\circ} \mathrm{C}$ for $5 \mathrm{~min}$ to induce heteroduplex formation during the subsequent step of slowly cooling down to room temperature, over thirty minutes. Five microliters of these PCR products was then automatically loaded onto the DNASep cartridge (Transgenomic Limited, UK) in the wave system. The specific acetonitrile 
Table I: NOD2/CARDI5 SNP8, I2 and 13 in patients with sporadic colorectal cancer (CRC) and (CD) and controls

\begin{tabular}{|c|c|c|c|c|c|c|}
\hline & \multicolumn{2}{|c|}{ R702W (SNP8) } & \multicolumn{2}{|c|}{ G908R (SNP I 2) } & \multicolumn{2}{|c|}{ 3020insC (SNP I3) } \\
\hline & CRC n (\%) & Controls n (\%) & CRC n (\%) & controls n (\%) & CRC n (\%) & controls n (\%) \\
\hline Wild type & $187(96.4)$ & $194(97.0)$ & $187(96.4)$ & $193(96.5)$ & $180(92.8)$ & $190(95.0)$ \\
\hline All Carriers & $7(3.6)$ & $6(3.0)$ & $7(3.6)$ & $7(3.5)$ & $14(7.2)$ & $10(5.0)$ \\
\hline Heterozygous & $7(3.6)$ & $6(3.0)$ & $7(3.6)$ & $7(3.5)$ & $14(7.2)$ & $10(5.0)$ \\
\hline Allele frequency & $7(1.8)$ & $6(1.5)$ & $7(1.8)$ & $7(1.8)$ & $14(3.6)$ & $10(2.5)$ \\
\hline $\begin{array}{l}P \text { value for } \\
\text { carriers }\end{array}$ & 0.78 & & 0.95 & & 0.40 & \\
\hline OR carrier $(95 \% \mathrm{Cl})$ & $1.21(0.39-3.67)$ & & $1.03(0.35-3.00)$ & & $\mathrm{I} .48(0.64-3.4 \mathrm{I})$ & \\
\hline
\end{tabular}

gradient to elute each exon was established by using the WaveMaker 3.4.4 software. The particular run temperature for the detection of each SNP was determined using positive controls, which were kindly provided by Dirk Seegert from Kiel, Germany.

Finally, when a sequence variation was observed in the dHPLC profile, the relevant PCR product was sequenced on both strands to confirm the alteration. Sequencing reactions were performed with the $\mathrm{ABI}$ BigDye terminator cycle sequencing kit v1.1 (Applied Biosystems, Foster City, CA, USA) and samples were sequenced on an ABI Prism 310 genetic analyzer (Applied Biosystems, Foster City, CA, USA).

\section{Statistical analysis}

Variables were tested for normality by Shapiro Wilk's W test. T-test with separate variance estimates, $\chi^{2}$-test and $\chi^{2}$ test with Yates correction were used to test differences between patients with CRC and controls, as well as within subgroups of CRC patients. Odds ratios (OR) and logistic regression were calculated to compare genetic and clinical data. A p value < 0.05 was considered statistically significant. For the statistical analysis, SPSS12.0 (SPSS Inc, Chicago, IL, USA) was used with the help of a statistician (Dr. Peter Vargha).

\section{Results}

A large number of CRC patients were diagnosed at an advanced stage (T stage III-IV: $76.2 \%$ ) and with clinical symptoms (57.7\%) as shown in Table 2. NOD2/CARD15 mutations were found in 28 patients $(14.4 \%)$ and in 23 controls (11.5\%, p = 0.45, OR: 1.29 (95\%CI: 0.72-2.34). Allele frequencies for SNP8/R702W (1.8\% vs $1.5 \%)$, SNP12/G908R (1.8\% vs. $1.8 \%)$ and SNP13/3020insC $(3.6 \%$ vs. $2.5 \%)$ were also not statistically different between CRC patients and controls (see Table 1). All patients and controls were heterozygous for a particular mutation, no homozygous or compound heterozygous carriers were identified.
There was no difference between the age at diagnosis in the group of patients harboring at least one mutation (mean age $64.5 \pm 7.9$ years old) compared to the patients without the mutations (mean age $63.0 \pm 9.3$ years old). Furthermore, the CARD15/NOD2 variants carrier status was not associated with any of the examined clinicopathologic variables (Table 2).

\section{Discussion}

Contrary to previous reports, in the present study we were unable to detect an association between the prevalence of common NOD2/CARD15 mutations and the risk for sporadic CRC in a Hungarian population. Comparable variant allele frequencies were observed in both, the patient and control groups.

A possible explanation for the differences between the previous studies and the present one may be the differences in carrier frequencies among the controls. An association between NOD2/CARD15 was initially reported by a Polish study in 2004 [25]. The incidence of CRC in Poland is high, similar to Hungary. An association between the 3020ins C mutation and the risk for CRC (OR: 2.23) was reported in 250 Polish CRC patients older than 50 years, at the time of time diagnosis. The carrier frequency was $14.4 \%$ in this subgroup of patients, however, it was only $7 \%$ in controls. This was not confirmed in patients who were younger than 50 years, at the time of diagnosis or in patients with HNPCC or a family history of CRC. In addition, no other common NOD2/CARD15 mutations were examined in the study.

In contrast, no association was found between the above mutation and the risk for CRC cases with or without family history in 926 CRC cases analyzed in a Finnish study. We have to note though, that the carrier (3.7\%) as well as allele frequencies (1.9\%) for both CRC patients and controls was lower in the Finnish study compared to the previous study as well as the present one. Variant allele frequencies in Finland (which by language is related to 
Table 2: Clinicopathologic characteristics of colorectal cancer patients (CRC) with respect to the presence or absence of NOD2I CARDI5 mutations

\begin{tabular}{|c|c|c|c|}
\hline & Total $(n=194)$ & Carrier $(n=28)$ & Non-carrier $(n=166)$ \\
\hline Male/female & $108 / 86$ & $17 / \mid 1$ & $91 / 75$ \\
\hline Age at diagnosis (years) & $63.2 \pm 9.1$ & $64.5 \pm 7.9$ & $63.0 \pm 9.3$ \\
\hline \multicolumn{4}{|l|}{ Age } \\
\hline$\leq 60$ years & 63 & 9 & 54 \\
\hline$>60$ years & $|3|$ & 19 & 112 \\
\hline \multicolumn{4}{|l|}{ Symptoms at diagnosis* } \\
\hline Yes & 112 & 20 & 92 \\
\hline No & 82 & 8 & 74 \\
\hline \multicolumn{4}{|l|}{ Tumor location } \\
\hline Rectum & 83 & 6 & 77 \\
\hline Left-colon & 73 & 15 & 58 \\
\hline Right colon & 38 & 7 & 31 \\
\hline \multicolumn{4}{|l|}{ T stage } \\
\hline I & 6 & 2 & 4 \\
\hline 2 & 40 & 6 & 34 \\
\hline 3 & 113 & 15 & 98 \\
\hline 4 & 35 & 5 & 30 \\
\hline \multicolumn{4}{|l|}{ N stage $\#$} \\
\hline 0 & 63 & 8 & 55 \\
\hline 1 or 2 & 86 & 10 & 76 \\
\hline
\end{tabular}

\footnotetext{
*symptoms: hematochezia, weight loss, anemia, changes in bowel movement habits \# data available in 149 patients

$\mathrm{P}=$ not significant, by $\mathrm{\kappa} 2$ or $\mathrm{T}$-test with separate variance estimates as appropriate
}

Hungary) were comparable to those previously reported in IBD patients [24]. The prevalence of $R 702 W, G 908 R$ and 3020 ins $C$ was $3.3 \%, 0.6 \%$ and $4.8 \%$, respectively, in the Finnish IBD study (in controls it was $1.8 \%, 0$ and $1.7 \%$ ) with only 3020 ins $C$ being more common in CD compared to controls. Noteworthy, unlike in the Polish study in the study by Alhopuro et al., [26] patients with an age older than 50 years at diagnosis did not have an increased frequency of 3020insC mutation (4.3\%) compared to patients with an age $<50$ years at the time of CRC diagnosis. In addition, no differences in the variant NOD2/CARD15 alleles were found between with any clinico-pathological characteristics.

The more recent study, from Greece, reported an association between all three common NOD2/CARD15 variants and the risk for sporadic CRC in 104 consecutive patients and 100 controls. Carrier frequencies in CRC patients were surprisingly high; $23 \%$ for 3020 insC, $9.6 \%$ for R702W and $13 \%$ for G908R compared to much lower rates in the controls $(12 \%, 2 \%$ and $7 \%$, respectively). In addition, carrier rates in CRC patients were comparable to the rates previously reported in Greek IBD patients [28]. Nonetheless, variant allele frequencies were much higher compared to the present study. In the most recent study by Roberts et al [29], not only SNP8 (OR: 2.3) were associated with the risk of sporadic CRC but also the presence of any common variant alleles (OR:2.8, 95\%CI: 1.5-5.4). In addition, two homozygous SNP8 carriers were detected in the CRC patient group. Male gender was associated to the carriage of variant allele.

In concordance with a previous report from Finland [26], we did not find any association between clinicopathological characteristics or the location of the CRC and the presence of NOD2/CARD15 variants. In contrast, in the Greek study [27], an association was found between the TNM stage at diagnosis and the presence of the variant NOD2/ CARD15 allele. NOD2/CARD15 variant alleles were associated with a more advanced TNM stage; however, partly due to the small number of patients, results were not corrected for other possible confounding factors (e.g. age at diagnosis or tumor differentiation). Finally, we have to note that according to previously published data (PolishGreek study) a patient number of between 175-280 would be necessary to detect the reported association with a type I error of 0.05 and a type II error of 0.10 , thus the present study had enough statistical power to detect the above differences in NOD2/CARD15 polymorphisms if present.

\section{Conclusion}

In summary, common NOD2/CARD15 mutations were not associated with disease susceptibility for sporadic CRC in a Hungarian population. This, in concordance with previous reports, suggests that it is unlikely that NOD2/CARD15 mutations alone are responsible for the development of sporadic CRC. 


\section{Competing interests}

The author(s) declare that they have no competing interests.

\section{Authors' contributions}

PLL: design of the study, collected patients, statistical analysis and drafted the manuscript; EH, FSZ, PF, LL, SF, JO, OG and JP: collected patients, reviewed the manuscript; GV: statistical analysis and drafted the manuscript; KZ: performed the DNA analysis, reviewed the manuscript; PF: design of the study, performed the DNA analysis, helped in drafting the manuscript. All authors read and approved the final manuscript.

\section{References}

I. Parkin DM: Global cancer statistics in the year 2000. Lancet Oncol 200I, 2:533-543.

2. Fuszek P, Horvath HC, Speer G, Papp J, Haller P, Fischer S, Halasz J, Jaray B, Szekely E, Schaff Z, Papp A, Bursics A, Harsanyi L, Lukovich P, Kupcsulik P, Hitre E, Lakatos PL: Location and Age at Onset of Colorectal Cancer in Hungarian Patients between 19932004. The High Number of Advanced Cases Supports the Need for a Colorectal Cancer Screening Program in Hungary. Anticancer Res 2006, 26:527-32.

3. Lakatos PL, Lakatos L: Current concepts on the genetics of hereditary and sporadic colorectal cancer and the role of genetics in the patient management. Orv Hetil 2006, 147:449-56.

4. Popat S, Wort R, Houlston RS: Inter-relationship between microsatellite instability, thymidylate synthase expression, and p53 status in colorectal cancer: implications for chemoresistance. BMC Cancer 2006, 6:150.

5. Fuszek P, Lakatos P, Tabak A, Papp J, Nagy Z, Takacs I, Horvath HC, Lakatos PL, Speer G: Relationship between serum calcium and Cal 9-9 levels in colorectal cancer. World J Gastroenterol 2004, I0:1850-52.

6. Balkwill F, Mantovani A: Inflammation and cancer: back to Virchow? Lancet 200I, 357:539-45.

7. Rhodes JM, Campbell BJ: Inflammation and colorectal cancer: IBD associated and sporadic cancer compared. Trends $\mathrm{Mol}$ Med 2002, 8: I0-6.

8. Eaden JA, Abrams KR, Mayberry JF: The risk of colorectal cancer in ulcerative colitis: a meta-analysis. Gut 200I, 48:526-35.

9. Lakatos L, Mester G, Erdelyi Z, David G, Pandur T, Balogh M, Fischer $S$, Vargha P, Lakatos PL: Risk factors for ulcerative colitis-associated colorectal cancer in a Hungarian cohort of ulcerative colitis patients. Results of a population-based study. Inflamm Bowel Dis 2006, I 2:205-II.

10. Higaki S, Akazawa A, Nakamur H, Yanai H, Yoshida T, Okita K: Metaplastic polyp of the colon develops in response to inflammation. J Gastroenterol Hepatol 1999, 17:709-14.

II. Jaiswal M, LaRusso NF, Burgart LJ, Gores GJ: Inflammatory cytokines induce DNA damage and inhibit DNA repair in cholangiocarcinoma cells by a nitric oxide-dependent mechanism. Cancer Res 2000, 60:184-90.

12. Sipos F, Molnar B, Zagoni T, Berczi L, Tulassay T: Growth in Epithelial Cell Proliferation and Apoptosis Correlates Specifically to the Inflammation Activity of Inflammatory Bowel Diseases: Ulcerative Colitis Shows Specific p53- and EGFR Expression Alterations. Dis Colon Rectum 2005, 48:775-86.

13. Lakatos PL, Fischer S, Lakatos L, Gal I, Papp J: Current concept on the pathogenesis of IBD: crosstalk between genetic and microbial factors. Pathogenic bacteria, altered bacterial sensing or changes in mucosal integrity take "toll"? World J Gastroenterol 2006, I 2:1829-40.

14. Berrebi D, Maudinas R, Hugot JP, Chamaillard M, Chareyre F, De Lagausie P, Yang C, Desreumaux P, Giovannini M, Cezard JP, Zouali $H$, Emilie $D$, Peuchmaur M: CARDI5 gene overexpression in mononuclear and epithelial cells of the inflamed Crohn's disease colon. Gut 2003, 52:840-846.
15. Bonen DK, Ogura Y, Nicolae DL, Inohara N, Saab L, Tanabe T, Chen FF, Foster SJ, Duerr RH, Brant SR, Cho JH, Nunez G: Crohn's disease-associated NOD2 variants share a signalling defect in response to lipopolysaccharide and peptidoglycan. Gastroenterology 2003, 124:140-146.

16. Maeda S, Hsu LC, Liu H, Bankston LA, limura M, Kagnoff MF, Eckmann $L$, Karin M: NOD2 mutation in Crohn's disease potentiates NF-kB activity and IL-Ib processing. Science 2005, 307:734-738.

17. Wehkamp J, Harder J, Weichenthal M, Schwab M, Schaffeler E, Schlee M, Herrlinger KR, Stallmach A, Noack F, Fritz P, Schroder JM, Bevins CL, Fellermann K, Stange EF: NOD2 (CARDI5) mutations in Crohn's disease are associated with diminished mucosal adefensin expression. Gut 2004, 53:1658-1664.

18. Netea MG, Kullberg BJ, de Jong DJ, Franke B, Sprong T, Naber TH, Drenth JP, Van der Meer JW: NOD2 mediates anti-inflammatory signals induced by TLR2 ligands: implications for Crohn's disease. Eur J Immunol 2004, 34:2052-9.

19. Buhner S, Buning C, Genschel J, Kling K, Herrmann D, Dignass A, Kuechler I, Krueger S, Schmidt HH, Lochs H: Genetic basis for increased intestinal permeability in families with Crohn's disease: role of CARD I5 3020insC mutation? Gut 2006, 55:342-7.

20. Hugot JP, Chamaillard M, Zouali H, Lesage S, Cezard JP, Belaiche J, Almer S, Tysk C, O'Morain CA, Gassull M, Binder V, Finkel Y, Cortot A, Modigliani R, Laurent-Puig P, Gower-Rousseau C, Macry J, Colombel JF, Sahbatou M, Thomas G: Association of NOD2 leucine-rich repeat variants with susceptibility to Crohn's disease. Nature 200I, 4I I:599-603.

21. Ogura Y, Bonen DK, Inohara N, Nicolae DL, Chen FF, Ramos R, Britton H, Moran T, Karaliuskas R, Duerr RH, Achkar JP, Brant SR, Bayless TM, Kirschner BS, Hanauer SB, Nunez G, Cho JH: A frameshift mutation in NOD2 associated with susceptibility to Crohn's disease. Nature 200I, 4 I I:603-6.

22. Ahmad T, Armuzzi A, Bunce M, Mulcahy-Hawes K, Marshall SE, Orchard TR, Crawshaw J, Large O, de Silva A, Cook JT, Barnardo M, Cullen S, Welsh KI, Jewell DP: The molecular classification of the clinical manifestations of Crohn's disease. Gastroenterology 2002, I 22:854-866.

23. Lakatos PL, Lakatos L, Szalay F, Willheim-Polli C, Osterreicher C, Tulassay Z, Molnar T, Reinisch W, Papp J, Mozsik G, Ferenci P: Tolllike receptor 4 and NOD2/CARD 15 mutations in Hungarian patients with Crohn disease: phenotype-genotype correlations. World J Gastroenterol 2005, I I : | 1489- | 495.

24. Helio T, Halme L, Lappalainen M, Fodstad H, Paavola-Sakki P, Turunen $U$, Farkkila M, Krusius T, Kontula K: CARD I5/NOD2 gene variants are associated with familially occurring and complicated forms of Crohn's disease. Gut 2003, 52:558-562.

25. Kurzawski G, Suchy J, Kladny J, Grabowska E, Mierzejewski M, Jakubowska A, Debniak T, Cybulski C, Kowalska E, Szych Z, Domagala W, Scott RJ, Lubinski J: The NOD2 3020insC mutation and the risk of colorectal cancer. Cancer Res 2004, 64:1604-6.

26. Alhopuro P, Ahvenainen T, Mecklin JP, Juhola M, Jarvinen HJ, Karhu $A$, Aaltonen LA: NOD2 3020insC is not sufficient for colorectal cancer predisposition. Cancer Res 2004, 64:7245-7.

27. Papaconstantinou I, Theodoropoulos G, Gazouli M, Panoussopoulos D, Mantzaris GJ, Felekouras E, Bramis J: Association between mutations in the CARD I5/NOD2 gene and colorectal cancer in a Greek population. Int J Cancer 2005, I I 4:433-35.

28. Gazouli M, Mantzaris G, Kotsinas A, Zacharatos P, Papalambros E, Archimandritis A, Ikonomopoulos J, Gorgoulis VG: Association between polymorphisms in the toll-like receptor $4, C D I 4$ and CARDI5/NOD2 and inflammatory bowel disease in Greek population. World J Gastroenterol 2005, I I :68 I-685.

29. Roberts RL, Gearry RB, Allington MDE, Morrin HR, Robinson BA, Frizelle FA: Caspase Recruitment Domain-Containing Protein 15 Mutations in Patients with Colorectal Cancer. Cancer Res 2006, 66:2532-2535.

\section{Pre-publication history}

The pre-publication history for this paper can be accessed here:

http://www.biomedcentral.com/1471-2407/7/54/prepub 